\title{
Religiões e Saúde: a experiência da Rede Nacional de Religiões Afro-Brasileiras e Saúde
}

\section{Religions and Health: the experience of the National Network of Afro-Brazilian Religions and Health}

\author{
José Marmo da Silva \\ Dentista, secretário-executivo da Rede Nacional de Religiões Afro- \\ Brasileiras e Saúde e integrante do Comitê Técnico de Saúde da \\ População Negra do Ministério da Saúde. \\ Endereço:Rua Franscisco Muratori, 6, apto 202, Santa Teresa, cep \\ 20230-080, Rio de Janeiro, RJ, Brasil, Fone: (21) 2224-4576. \\ E-mail: redeterreirosaudeळhotmail.com; mguimarळuol.com.br
}

\section{Resumo}

Este artigo visa mostrar a experiência da Rede Nacional de Religiões Afro-Brasileiras e Saúde na construção de uma parceria com o Sistema Único de Saúde (SUS), as práticas terapêuticas utilizadas pelos terreiros e as relações da religiosidade afro-brasileira com os agravos e as doenças. A importância dos cuidados com o corpo para as religiões afro-brasileiras foi o ponto de partida para a realização da experiência do agir em rede, em que as lideranças das religiões de matrizes africanas vivenciaram situações que possibilitaram entender o funcionamento do SUS, avaliar os serviços prestados a população e reconhecer a importância do controle social das políticas públicas de saúde. Em contrapartida, mostra também o estabelecimento de um canal de interlocução que possibilitou aos sacerdotes e sacerdotisas da tradição religiosa afro-brasileira uma aproximação maior dos gestores e profissionais de saúde facilitando o diálogo e a proposição de ações em saúde que respeitassem a cultura e a visão de mundo dos terreiros. Finalmente apresenta alguns dos resultados e desafios enfrentados pela Rede Nacional de Religiões e Saúde na sua trajetória de ações em parceria com o SUS.

Palavras-chave: Religiões afro-brasileiras; Saúde da população negra; Controle social; Práticas terapêuticas. 


\section{Abstract}

The present report aims to show the experience of the National Network of Afro-Brazilian Religions and Health in the construction of a partnership with SUS (National Health System), the therapeutic practices used by the terreiros and the relationships of the AfroBrazilian religiosity to injuries and diseases. The importance of body care to the Afro-Brazilian religions was the point-of-departure to carry out the experience of acting in network. In this experience, the leaderships of African religions underwent situations that promoted the understanding of the functioning of the National Health System/SUS, the evaluation of the services provided for the population, and the recognition of the importance of the social control of public health policies. The report also shows the establishment of an interlocution channel that promoted an approximation between the priests and priestesses of the Afro-Brazilian religious tradition and the health managers and professionals, facilitating the dialog and the proposition of health actions, respecting the culture and worldview of the terreiros. Finally, it presents some results and challenges faced by the National Network of Afro-Brazilian Religions and Health in its trajectory of actions in partnership with SUS.

Keywords: Afro-Brazilian Religions; Black Population's Health; Social Control; Therapeutic Practices.

\section{A Rede Nacional de Religiões Afro- Brasileiras e Saúde}

As religiões afro-brasileiras mantiveram-se, ao longo dos anos, como foco de resistência cultural negra, formando uma estrutura que marca de forma significativa a cultura brasileira. São mais de 30.000 terreiros espalhados pelo país, constituindo as diversas expressões das religiões de matrizes africanas no Brasil (Silva, 2003). Em função da especulação imobiliária e da necessidade de espaços que possibilitassem contato maior com a natureza, os terreiros encontram-se localizados em subúrbios ou periferias das cidades, áreas geralmente desprovidas de equipamentos e recursos sociais.

Os templos afro-religiosos constituem-se, há séculos, em espaços de inclusão para os grupos historicamente excluídos, de acolhimento e de aconselhamento. As práticas rituais e as relações interpessoais que são estabelecidas nestes espaços possibilitam as trocas afetivas, a produção de conhecimento, o acolhimento, a promoção à saúde e a prevenção de doenças e agravos, bem como a renovação de tradições milenares, sobretudo por meio do uso das plantas medicinais.

É nesses espaços, denominados roças ou comunidades de terreiro, onde a sabedoria dos mais velhos se funde à vocação para aprendizagem dos mais novos, que desenvolvemos o nosso trabalho de ações de promoção da saúde em rede.

Os terreiros constituem-se como focos de resistência cultural negra, mas também funcionam como pólos de difusão de informações e trocas de saberes, que muitas vezes não são reconhecidos pela classe dominante (Sodré, 1988).

A promoção da saúde nesses espaços é fundamental, pois permite a preservação da própria tradição religiosa, uma vez que o corpo é um dos elos de ligação com os deuses e deusas. A saúde é vivenciada pelos adeptos como o equilíbrio das forças vitais ou a harmonia com a natureza, como verificamos em muitas de nossas ações e encontros realizados pela Rede Nacional de Religiões Afro-Brasileiras e Saúde.

A Rede foi criada em março de 2003 durante o II Seminário Nacional Religiões Afro-Brasileiras e Saúde (São Luis-MA) sendo uma instância de articulação da sociedade civil que envolve adeptos da tradição religiosa afro-brasileira, gestores/profissionais de saú- 
de, integrantes de organizações não-governamentais, pesquisadores e lideranças do movimento negro.

A Rede tem como objetivos lutar pelo direito humano à saúde; valorizar e potencializar o saber dos terreiros em relação à saúde; monitorar e intervir nas políticas públicas de saúde exercendo o controle social; combater o racismo, sexismo, homofobia e todas as formas de intolerâncias; legitimar as lideranças dos terreiros como detentores de saberes e poderes para exigir das autoridades locais um atendimento de qualidade, em que a cultura do terreiro seja reconhecida e respeitada; estabelecer um canal de comunicação entre os adeptos da tradição religiosa afro-brasileira, os gestores, profissionais de saúde e os conselheiros de saúde.

Atualmente a Rede Nacional de Religiões Afro-Brasileiras e Saúde conta com mais de 300 organizações divididas em 23 núcleos espalhados pelo país e representações em 12 estados. Para atingir seus objetivos a Rede Nacional de Religiões Afro-Brasileiras e Saúde vem realizando, desde a sua criação, uma série de atividades nos estados e municípios com o objetivo de instrumentalizar e potencializar os saberes das lideranças de terreiros para o exercício do controle social de políticas públicas de saúde. A série de seminários nacionais tem a finalidade de sensibilizar os gestores e profissionais de saúde sobre os impactos das desigualdades raciais e da intolerância religiosa no campo da saúde e incentiva ações que possam fortalecer a eqüidade no SUS.

\section{Os primeiros passos para a formação da Rede}

O reconhecimento da diversidade das religiões de matrizes africanas no Brasil e a possibilidade de uni- las em torno de um objetivo que faça parte do cotidiano de todas, como os cuidados com o corpo e manutenção da saúde, foi o nosso ponto de partida para o desenvolvimento deste trabalho.

O passo seguinte foi a realização de um levantamento na Baixada Fluminense, no Rio de Janeiro, e em São Luis, no Maranhão, com a finalidade de conhecer os motivos pelos quais as pessoas procuram os terreiros, assim como a dimensão que a saúde e a doença têm entre os adeptos da tradição religiosa afrobrasileira.

Os motivos apresentados pelos adeptos foram os seguintes: a busca espiritual, a tradição familiar, a dificuldade financeira e os problemas amorosos. Porém vale ressaltar que ao serem indagados se esses motivos tinham alguma repercussão ou influência nos seu estado de saúde, $80 \%$ disseram que sim.

O mesmo levantamento também procurou listar os problemas de saúde mais freqüentes nos terreiros e entre esses podemos destacar: dor de cabeça, desmaio, depressão, problemas de visão, taquicardia, hipertensão, doença desconhecida pelos médicos, amnésia, doenças de pele, febre reumática, convulsões, alcoolismo, insônia, doença dos nervos e doenças da barriga.

Verificamos que a maioria dos problemas é de origem psicossomática e que as práticas terapêuticas dos terreiros contribuíam para minimizá-los ou acabar com eles.

Na perspectiva de aprofundar o levantamento procuramos saber se os deuses e deusas tinham alguma relação com os problemas de saúde mencionados e fizemos um recorte nos terreiros de candomblé (nação ketu) para essa atividade, conforme demonstrado no quadro abaixo:

\begin{tabular}{|l|l}
\hline Sintomas, agravos e doenças & Deuses (as) \\
\hline Doenças epidêmicas (variola, AIDS) e doenças de pele & Obaluaiê \\
\hline Aborto, infertilidade feminina, problemas menstruais, etc. & lemanjá e Oxum \\
\hline Impotência e infertilidade masculina & Xangô e Exu \\
\hline Problemas de visão & Oxum \\
\hline Asma, falta de ar e problemas respiratórios & Iansã \\
\hline Distúrbios emocionais & Oxossi e Ossain \\
\hline Males do fígado, vesícula e úlceras estomacais & Oxossi e Logun-Edé \\
\hline Obesidade & lemanjá, Oxum e Xangô
\end{tabular}


Verificamos também que no tambor de mina do Maranhão, os voduns, os caboclos e os encantados têm influência no estado de saúde das pessoas como pudemos constatar na fala de alguns dos nossos entrevistados: "eu fui internada várias vezes e os médicos diziam que eu tinha problema de cabeça. Um dia eu fugi e fui para dentro de um terreiro de mina. Foi lá que me curei”.

Outra entrevistada relatou o seguinte caso: "minha barriga começou a inchar e os médicos me mandaram fazer vários exames e não conseguiam saber o que eu tinha. 0 próprio médico acabou me recomendando procurar [um] doutor do mato. Eu relutei, mas fui, e lá chegando o caboclo no terreiro passou uns negócios na minha barriga e me receitou umas ervas. A barriga voltou ao normal e nunca mais tive nada”.

0 trabalho desenvolvido pela Rede permitiu reconhecer a importância desses relatos para a troca de conhecimentos e de informações sobre as práticas terapêuticas dos terreiros e entender como esses espaços religiosos lidam com a saúde.

Conhecer o perfil dos adeptos dos terreiros nas cidades do Rio de Janeiro e de São Luis também foi um instrumento importante para a proposição das ações de saúde e as características das populações envolvidas: negros e negras, de baixa renda, com pouca escolaridade, moradores de subúrbios e de periferia, o que já nos mostrava que seria importante um trabalho envolvendo questões raciais, de gênero e de direitos humanos. O levantamento realizado nestes dois universos (Rio e São Luis) apresentou diferenças no que se refere às políticas públicas, entre elas, de educação e de saúde - e as demais condições socioeconômicas que influenciam no Índice de Desenvolvimento Humano (IDH) nas diversas regiões do Brasil.

O Maranhão é apontado como um dos estados mais deficitários no que diz respeito ao IDH enquanto o Rio de Janeiro ocupa melhor posição. Apesar dessas diferenças relativas ao IDH confirmam-se as dificuldades que a população dos terreiros e a população negra enfrentam, em ambos os estados, no acesso e na utilização dos equipamentos sociais, colocando-as em condições de maior vulnerabilidade ao adoecimento.

\section{Os terreiros $e$ a arte de cuidar}

Para as religiões afro-brasileiras o corpo é a morada de deusas e deusas e por isso necessita de cuidados. Inkices, voduns, orixás, caboclos, pretos-velhos, pom- bas-gira e encantados necessitam do corpo dos iniciados para trazer suas mensagens para os seres humanos (Silva, 1994).

O cuidado com o corpo pode ser observado na fala de Mãe Beata de Iemanjá (mãe de santo do Ilê Omi Ojuarô-RJ): "A cabeça é o jarro cheio de rosas maravilhosas e o corpo é a mesa que sustenta esse vaso. Se a mesa estiver com o pé quebrado o jarro vai cair e quebrar". Ela chama a nossa atenção para a importância do equilíbrio das partes para manutenção do bom funcionamento do todo.

Nos terreiros a saúde acontece em três dimensões: saúde mental, saúde do corpo e saúde espiritual. A noção de saúde e doença está associada ao conceito de axé - energia da vida. 0 axé como energia pode aumentar ou diminuir causando o equilíbrio ou o desequilíbrio (Santos, 1986).

A doença para as religiões afro-brasileiras pode ser considerada um desequilíbrio ou uma ruptura entre os mundos dos humanos e o mundo sobrenatural. Muitas vezes uma experiência, entendida na lógica da medicina oficial como distúrbio do corpo físico e/ou da mente, são para as religiões afro sinais ou manifestações de deuses e deusas. Exemplo disso são os casos de iniciações por problemas de saúde.

Vários são os procedimentos utilizados para o reequilíbrio das pessoas e alguns deles serão relacionados a seguir: o jogo de búzios, os ebós, o bori, as iniciações, o uso das folhas, ervas raízes e flores, os banhos, as benzeduras, as beberagens, o aconselhamento, etc. Cada tradição religiosa afro-brasileira utiliza um procedimento ou combinações de procedimentos visando restabelecer a saúde das pessoas.

No jogo de búzios, o sacerdote ou a sacerdotisa além descobrir o problema que aflige a pessoa (o consulente), repassa também o que é preciso fazer para solucioná-lo. 0 jogo de búzios também permite aconselhar as pessoas para escolher o melhor caminho a seguir. O bori, que quer dizer dar comida à cabeça, é fundamental para fortalecer a cabeça do indivíduo e fortalece também os laços com a comunidade e com a própria tradição. Enfim podemos dizer que todos os procedimentos rituais são também procedimentos terapêuticos, pois envolvem cuidado, carinho e atenção, propiciando o reforço da energia vital (axé).

Para Makota Valdina (candomblé, nação angola) uma pessoa saudável está na linha de kalunga que é a linha do equilíbrio, simbolizada por uma linha hori- 
zontal; quando está doente, uma extremidade dessa linha desce e outra sobe tornando-a inclinada, indicando um desequilíbrio energético. Valdina afirma que "a cura das doenças na perspectiva das religiões afro envolve a ação dos dois mundos: material e imaterial, visível e invisível. Nada ocorre nessa tradição religiosa sem a interação desses dois mundos. Muitas vezes um desequilíbrio físico é provocado por um desequilíbrio espiritual e vice-versa. Apesar de sabermos que muitas doenças precisam ser tratadas pela medicina dos cientistas, se a pessoa é iniciada, quase sempre busca antes o terreiro para se curar e sempre busca a cura dos dois lados".

0 povo de santo sabe que existem algumas doenças ou desordens que os médicos desconhecem e, portanto, não conhecem os procedimentos de cura como é o caso do mau-olhado, quebranto e espinhela caída. Nesse sentido a sabedoria dos terreiros e as suas práticas terapêuticas são fundamentais para lidar com o sofrimento das pessoas e o restabelecimento da saúde.

Os modelos de intervenção nos terreiros, como já vimos anteriormente, incluem atenção e cuidado no atendimento. Faz parte do processo terapêutico a escuta do consulente, um modelo que certamente poderia inspirar políticas públicas de saúde e que está de acordo com o que é preconizado pela Organização Mundial de Saúde.

A atenção à saúde nos terreiros inclui: o acolhimento e suporte, o toque no corpo, o respeito aos idosos e ao saber dos mais velhos, a celebração da vida e do nascimento, o respeito às orientações sexuais, o equilíbrio psicossocial, a inclusão de todos, entre outros aspectos. Percebemos que as religiões afro-brasileiras, por intermédio da sua visão de mundo integradora, propõem uma forma de lidar com os conflitos e os paradoxos da vida. Muitas vezes o sofrimento se dá pela dificuldade de encontrar formas de solucionar o conflito que se estabelece entre o desejo e as possibilidades que a vida apresenta ( Guimarães, 1998).

A visão de mundo dos terreiros que está no ritual, no cuidado, na construção de uma linha de continuidade de ser, de inclusão num processo histórico, de territorialização, de pertencimento a uma família mítica e humana cria um campo de mediação que facilita o escoamento da tensão psíquica que se cria entre aquilo que queremos (desejo) e o que é possível (limite) (Guimarães, 1990).
A tradição religiosa afro-brasileira possui um acúmulo de saberes relacionados à saúde que são reforçados pelas lendas conforme relataremos a seguir: "Quando Orumilá, o testemunho do destino dos seres humanos, veio ao mundo, pediu a um ajudante de nome Ossain - guardião dos segredos das folhas para lavrar seu campo. Na hora de começar o seu trabalho, Ossain percebeu que ia cortar a erva que curava a febre. E então gritou: 'impossivvel cortar esta erva, pois é muito útil!'. A segunda curava dores de cabeça e Ossain recusou-se também a destruí-la. A terceira suprimia as cólicas. Na verdade, disse ele: 'não posso arrancar ervas tão necessárias', Orumilá, tomando conhecimento da conduta do seu ajudante, demonstrou o desejo de ver estas ervas que Ossain se recusava a cortar. Elas tinham um grande valor, pois contribuíam para manter o corpo em boa saúde. Orumilá decidiu então que Ossain ficaria sempre ao seu lado na hora das consultas para explicar-lhe as virtudes das plantas, das folhas e das ervas. Estas são trazidas em uma cabaça, misturadas e guardadas visando restabelecer a saúde."

\section{As Ações da Rede Nacional de Religiões Afro-Brasileiras e Saúde}

A Rede desenvolve várias atividades visando o empoderamento das lideranças da tradição religiosa afrobrasileira para o exercício do controle social de políticas públicas. Para isso conta com profissionais de educação e saúde iniciados ou simpatizantes dos terreiros que desenvolvem ações nos diversos núcleos espalhados pelo país e mães e pais de santo gerenciando cada núcleo da Rede.

Entre essas atividades destacamos: a elaboração de materiais educativos, com códigos e visão de mundo dos terreiros (vídeos, livros, folders, boletins, informes), a capacitações dos núcleos, os encontros, as realização de seminários nacionais, a participação em eventos, a participação nos mecanismos de controle social.

No início, o apoio do Programa de Combate ao Racismo Institucional (PCRI) foi importante para qualificar as nossas ações. 0 estabelecimento de parcerias dos núcleos da Rede com as Secretarias de Saúde local permitiram o desdobramento de algumas ativida- 
des atualmente garantidas no PPA (Plano Pluri-Anual) e no PAM (Plano de Ações e Metas) como ações direcionadas para as populações de terreiros.

Até o presente momento foram realizados uma série de seminários nacionais (sete), com os seguintes objetivos: refletir sobre os impactos do racismo e da intolerância religiosa na saúde da população negra e do povo de santo, contribuir na proposição de políticas públicas de saúde voltadas para a população dos terreiros e para a população negra visando à promoção da eqüidade no SUS; estimular os adeptos dos terreiros na gestão participativa e controle social das políticas públicas de saúde; sensibilizar os gestores e profissionais de saúde para o reconhecimento do saber da tradição religiosa afro-brasileira e o respeito à cultura dos terreiros nas ações, projetos e programas de saúde governamentais; conhecer os aspectos religiosos que influenciam a saúde; apresentar os modelos e as práticas dos terreiros relacionadas ao acolhimento, aos cuidados e à solidariedade para o enfrentamento dos problemas de saúde.

\section{As capacitações realizadas pela Rede}

Uma das atividades que consideramos importante e fundamental para o crescimento e o fortalecimento da Rede foram as capacitações realizadas com dupla finalidade: instrumentalizar os adeptos dos terreiros para o controle social e a sensibilização dos gestores/ profissionais de saúde para lidar com os problemas de saúde vivenciados pelos terreiros respeitando a visão de mundo dessa tradição religiosa.

Algumas premissas foram fundamentais para o desencadeamento do processo de capacitação:

- o levantamento do perfil dos participantes na lista de adesões da Rede;

- a elaboração de um Plano de Ação dos participantes para o desenvolvimento de ações em Rede em suas cidades de origem após a capacitação;

- a criação e a legitimação de uma metodologia que possibilitasse o envolvimento de todos os participantes;

- a contato com profissionais de saúde, serviços de saúde e conselhos de saúde das cidades envolvidas na capacitação para estreitar laços de apoio mútuo;

- a escolha das cidades e dos locais para a realização da capacitação que possibilitasse aos grupos convidados de outras cidades conhecerem outras realidades;
- a garantia da presença dos gestores de saúde na capacitação.

Para a capacitação dos núcleos locais da rede, contando com a adesão de profissionais de secretarias de governos das áreas de saúde, educação e cultura e representantes de organizações não-governamentais, privilegiou-se a questão do exercício do controle social das políticas públicas de saúde, em uma perspectiva de rede.

A operacionalidade da rede, suas interfaces, estratégias, dinamicidade, capacidade de traçar diagnóstico, fazer encaminhamentos, acompanhar denúncias, listar potenciais e as dificuldades para um trabalho desta natureza também foram exercitados nas capacitações.

Os grupos de trabalho, por meio de alguns estudos de caso, tiveram a oportunidade de simular - a partir da idéia de que aquelas situações poderiam ser levadas até o terreiro - uma ação em rede para o controle social.

Os estudos de casos possibilitaram aos participantes refletir sobre situações que podem acontecer no dia-a-dia dos terreiros e a necessidade de respostas para a sua resolução. As capacitações permitiram também a realização de um diagnóstico da realidade local em termos de saúde e atendimento aos usuários. O diagnóstico foi compreendido como uma necessidade para: conhecer, avaliar, fiscalizar, questionar, participar, monitorar, denunciar, entender, cuidar, reavaliar os serviços de saúde prestados à população.

Algumas experiências exitosas na saúde também foram ressaltadas como os hospitais e maternidades amigas da criança, um exemplo da viabilidade de serviços que podem ser estimulados e seguidos por outras áreas da saúde.

\section{Os principais desafios enfrentados pela Rede}

Na sua trajetória a Rede teve que enfrentar alguns desafios devido ao olhar de gestores e profissionais de saúde em relação às religiões afro-brasileiras. Verificamos desde o início certo desconforto na aproximação do SUS e os terreiros, tendo como foco o desconhecimento por parte dos profissionais sobre essa tradição religiosa, o preconceito e a idéia de que as religiões afro-brasileiras praticam o mal.

Isso pode ser comprovado em várias capacitações, principalmente com as equipes do Programa de Saúde 
da Família (PSF) que não entravam nos terreiros para realizar visitas de rotina, pois tinham medo ou receio que algo acontecesse.

Os terreiros por sua vez reclamavam que o PSF não os atendia e com isso não cumpria o que estava garantido por lei, na Constituição: o direito humano à saúde.

Outro desafio foi lidar com a intolerância religiosa, uma vez que grande parte das equipes de saúde é formada por pessoas de outras religiões (católicos e evangélicos), que muitas das vezes dificultam o acesso dos adeptos aos serviços oferecidos pelo SUS.

As equipes de saúde também reclamavam que alguns adeptos vão contra as orientações prescritas pelos médicos e atrapalham o tratamento. "Os adeptos confiam mais nos pais e mães de santo do que em nós", fala do médico.

As capacitações da Rede serviram para discutir essas questões e criar um plano estratégico que possibilitasse o enfrentamento dessas dificuldades, envolvendo as lideranças dos terreiros e os profissionais de saúde.

\section{Alguns resultados do trabalho em rede}

As ações empreendidas pela Rede Nacional de Religiões Afro-Brasileiras e Saúde permitiram ao longo do processo alguns resultados:

- o fortalecimento da Rede e a construção de visibilidade nas três esferas de governo (federal, estadual e municipal);

- intercâmbio entre sacerdotes e sacerdotisas das diversas religiões de matrizes africanas;

- a inclusão dos terreiros em ações do SUS em várias cidades;

- o estreitamento das relações entre os gestores/profissionais de saúde e as lideranças de terreiros;

- a sensibilização dos gestores/profissionais de saúde em relação à intolerância religiosa, desfazendo os mecanismos de defesa em relação aos terreiros;

- o maior envolvimento das lideranças de terreiros nos mecanismos de controle social de políticas públicas de saúde, como, por exemplo, participação nos conselhos de saúde conferências de saúde;
- a inclusão do respeito aos saberes e valores das religiões de matrizes africanas na Política Nacional de Atenção Integral à Saúde da População Negra (aprovada em novembro de 2006 pelo Conselho Nacional de Saúde);

\section{Conclusão}

As religiões afro-brasileiras possuem um modelo de cuidado e atenção à saúde que tem repercussão na melhoria da qualidade de vida dos adeptos e da comunidade do entorno. Os terreiros reúnem um repertório simbólico e real de alternativas de informação/ educação/atendimento na prática de lidar com a saúde e com a educação, podendo tornar-se importante instrumento estratégico para o enfrentamento de várias doenças e para a promoção da saúde.

Os processos defensivos envolvendo os profissionais de saúde e as lideranças de terreiros, no início da aproximação dos dois grupos, foram sendo substituídos por atitudes de compreensão de um desafio que deveria ser ultrapassado, gerando novas atividades em parceria.

\section{Referências}

GUIMARÃES, M. A. É um umbigo, não é?: a mãe criadeira, um estudo sobre o processo de construção de identidade em comunidades de terreiro. 1990. Dissertação - Pontifícia Universidade Católica do Rio de Janeiro, Rio de Janeiro, l99o.

GUIMARÃES, M. A. C. A área de ilusão e a subjetividade afro-descendente no Brasil. Arayê, Rio de Janeiro, ano II, set. 1998, p. 17-22. Número especial.

SANTOS, J. E. Os Nagô e a morte: Padê, Asese e o culto Egun na Bahia. Petrópolis: Vozes, 1986.

SILVA, J. M. (Org.). Religiões afro-brasileiras e saúde. São Luis: Centro de Cultura Negra do Maranhão, 2003.

SILVA, J. M. AIDS e religiões afro-brasileiras. Boletim $A B I A$, Rio de Janeiro, n. 26, p. 10, 1994.

SODRÉ, M. O terreiro e a cidade. Petrópolis: Vozes, 1988. 